\title{
Filósofas em rede: reagregando o público e o privado em tempos de catástrofes*
}

\author{
Women Philosophers in network: Re-Agsresating the Public \\ and the Private in Times of Catastrophes
}

Dnda. Maria Helena Silva Soares - PPGFIL UERJ

helenastraub@gmail.com

ORCID: https://orcid. org/0000-0002-5421-2151

Data de recebimento: 09/09/2020 Data de aceite: 01/10/2020

\section{Nova Iguaçu, 20 de agosto de 2020}

\section{Às mulheres acadêmicas periféricas ${ }^{1}$ que romperam com o esperado} para seus corpos e impõem à história seu escrever.

Enquanto decido por este estilo de escrita que mescla a função de carta e ensaio, por ter tanto a função do endereçamento quanto a de percorrer de modo crítico um tema em sua complexidade, ainda que sem a pretensão de esgotar suas questões persistentes; completamente influenciada pelas línguas de Gloria Anzaldúa (ANZALDÚA, 2000) e pelo chamado de Virginia Woolf (WOOLF, 2020 e 2014); ouço um estouro e a luz se apaga. Rapidamente ela volta, mais um estouro e já não contamos com nenhuma esperança de ter luz pelas próximas horas. No verão, são frequentes os dias em que isso ocorre. Os responsáveis pelo fornecimento alegam que como há mais pessoas em casa, por conta das férias escolares, há um aumento considerável no consumo de energia, sobretudo por causa dos aparelhos de ar condicionado, que permitem a alguns ter uma vida mais digna nos dias mais quentes, que faz com que haja uma sobrecarga na rede. Contam também que isto também se dá por causa de instalações clandestinas que causam problemas na rede.

A justificativa dada, a sobrecarga de energia, seja pelo alto consumo ou pela falta de manutenção, que aliás hora nenhuma é assumida,

1 Usamos o termo periféricas e periferia, ao longo do texto, enquanto uma situação à margem geográfica, social, econômica e/ou politicamente em relação aos centros. 
seria talvez plausível se ocorresse o mesmo em outras cidades, como a capital do Rio de Janeiro, que não apresenta o problema com a mesma frequência. Poderíamos fazer uma análise com recorte de território para outros serviços essenciais, como o acesso à água, segurança, transporte, moradia, circulação ou cultura. Ainda que Nova Iguaçu e outras cidades da Baixada Fluminense estejam localizadas próximas à estação de tratamento e distribuição de água, passam-se dias inteiros de verão sem que o serviço seja prestado e há lugares em que a escassez é rotina independente da estação. O que sinaliza, doutores, que lavar as mãos em tempos de pandemia não é apenas o resultado de uma decisão pessoal fundamentada em um trabalho virtuoso da razão.

Estamos debaixo da linha do equador, é inverno e os mesmos problemas se impõem. O fato é que a falta de acesso a recursos essenciais constitui há muito uma rotina para a periferia, não seria diferente em tempos de crise. A pandemia provocada pela existência de um vírus com alta capacidade de contaminação pelas vias aéreas fez com que a distinção entre o tratamento dado às populações da margem ao centro ficasse ainda mais evidente e refletisse diretamente no ainda crescente número de contaminados e mortos pela COVID-19. A contaminação por um agente biológico invisível facilitou, de início, a narrativa de que estaríamos todos em igual medida expostos ao risco iminente. Estamos no mesmo barco, eles disseram. Afinal, a doença não distinguiria ninguém, em uma decisão democrática explicada apenas pela carga viral designada ao indivíduo. Essa hipótese é refutada quando os marcadores de classe e território apontam que há um aumento significativo de casos de contaminação e morte entre aqueles que dependem do transporte público, ou seja, os trabalhadores precarizados.

Escrevo esse ensaio a fim de apontar os problemas dessa visão que pretende uma vez mais universalizar nossas experiências, sem, contudo, observar as diversidades que nos atravessam e impedem que muitos possam se proteger efetivamente. A ideia de uma visão de lugar nenhum impede um testemunho responsável sobre os acontecimentos e, consequentemente, alteram a produção e a confiabilidade do conhecimento objetivo. Por isso, escrevo hoje para, sobre e pelas mulheres que, como eu, se veem nesse lugar de fronteira: entre os marcadores que nos identificam e diferenciam em tempos de crise sanitária, política, epistêmica e moral.

Para isso, abordarei a situação da mulher periférica e acadêmica no tempo presente, a partir de três temas fundamentais para sua localização: a casa, o trabalho e o conhecimento. Vistos assim, desde pelo menos a origem da ciência moderna, muitos dos meus colegas filósofos interromperiam a leitura por afirmar que tal percurso deve ser produzido por outras ciências, como a etnografia e os estudos culturais. Partimos de uma epistemologia feminista que entende o conhecimento como parcial, situado e corporificado e, portanto, a filosofia não apenas não pode se isentar de uma visão crítica sobre o presente como é abertamente conclamada a pensá-lo quando vivenciamos tempos de incertezas.

A ciência moderna, europeia e masculina naturalizou uma espécie de sujeito, uma testemunha onisciente e onipresente, capaz de apresentar-se para além de qualquer suspeita. A principal virtude desse tipo de construção do conhecimento é a sua pretensa modéstia (SCHAPIN; SCHAFFER, 1995) garantida pela ausência de vínculo com aspectos da vida privada, que lhe conferiu, historicamente, hegemonia de saber e poder. Como afirma Donna Haraway, este sujeito modesto é como um ventríloquo legítimo e autorizado a estabelecer os fatos. Sua subjetividade é sua objetividade (HARAWAY, 2018, p.24), mas isso nem sempre é dito claramente. A historiografia e a filosofia feitas sobre a ciência contribuíram para uma construção de narrativa muitas das vezes falaciosa quanto ao seu caráter de neutralidade. Este ensaio tensiona uma abordagem parcial sobre a pandemia, a fim de que mais atores, aqui especificamente trato das mulheres acadêmicas periféricas, possam construir essa narrativa.

Não pretendo com isso advogar a favor de uma produção de influência norte-americana dos anos sessenta do século passado, que enaltece um tipo ideal de feminilidade sacralizada. Ao contrário, este ensaio-carta só cumprirá seu objetivo se for capaz de ser lido e correspondido por toda e qualquer e dialogar com uma pluralidade de mulheres. Uma voz do feminismo plural que entende não haver transformação sem radicalização do pensamento dedicado à emancipação de todas e todes que sofrem com segregações de gênero, raça, classe, territorial, geracional, dentre outras. 


\begin{abstract}
Esqueça o quarto só para si - escreva na cozinha, tranque-se no banheiro. Escreva no ônibus ou na fila da previdência social, no trabalho ou durante as refeições, entre o dormir e o acordar. Eu escrevo sentada no vaso. Não se demore na máquina de escrever, exceto se você for saudável ou tiver um patrocinador - você pode mesmo nem possuir uma máquina de escrever. Enquanto lava o chão, ou as roupas, escute as palavras ecoando em seu corpo. Quando estiver deprimida, brava, machucada, quando for possuída por compaixão e amor. Quando não tiver outra saída senão escrever.
\end{abstract}

Gloria Anzaldúa, Falando em línguas: uma carta para mulheres escritoras do terceiro mundo, 2008, p.233.

Apenas cinquenta e dois anos e um oceano inteiro separam a publicação de Um teto todo seu (1929), de Virginia Woolf, e Falando em línguas (1981), de Anzaldúa. Enquanto a escritora inglesa afirmava que a emancipação feminina dependia de uma inserção no universo letrado possibilitado por uma situação material bem definida, a escritora chicana alerta que para mulheres do terceiro mundo essa esperança se transforma em limitação. É preciso escrever, ainda que já sejam três da manhã e a luz não tenha voltado. É preciso ter como meta a escrita mesmo que todo o presente não inspire qualquer confiança quanto a essa atividade. Escreve-se, acima de tudo, por não ter outro modo de fazer-nos vir ao mundo, de tornarmo-nos aquilo que somos através do ato político de contar nossa própria história (KILOMBA, 2019, p.27-28) e, assim, fazer com que nossas vozes se amplifiquem.

\title{
22 de agosto de 2020
}

Orientações distintas que partem do mesmo pressuposto: a emancipação feminina virá de sua conquista pessoal do espaço público a partir do espaço privado, seja ele propício ou não ao seu desenvolvimento. Contudo, representatividade sem história e política não altera a estrutura, o cerne do problema que buscamos traçar. A presença de mulheres periféricas na academia e a sua escrita operam agora pela subversão ao pensamento colonial, do qual foram formadas, para promover uma efetiva mudança estrutural que estabeleça novos espaços de saber e poder. Para nós, nunca houve a possibilidade, isso se intensifica agora em tempos de pandemia, de afastar-nos completamente das demandas da casa. Talvez por não termos conquistado uma mudança significativa quanto aos direitos sobre nossos corpos, seguimos nesse lugar que nos é imposto ainda que indiretamente sob a normatização do cuidado, naturalizado pela instrução precoce e perene, como uma condição feminina.

Como competir em justa simetria com uma parcela significativa da população que foi, desde sempre, orientada ao sucesso pessoal no espaço público? Não foi preciso chegar às cadeiras universitárias ou debater sobre o que é o esclarecimento; experiência masculina branca no mundo é forjada para a política, mais especificamente, para o sucesso nas disputas pelo poder. A disputa assimétrica também pode ser verificada nas origens da ciência moderna ocidental, desde pelo menos o fim da idade média, como na Querelle des femmes ${ }^{2}$ em que argumentos misóginos e filóginos conviviam no espectro formador desde eruditos aos revolucionários das luzes. Esses rastros do feminismo para além dos movimentos sociais indicam que a mera acusação de identidarismo que o pensamento feminista sobre ciência recebe de seus detratores se iguala ao projeto de

2 A disputa por um significado único para isso a que chamamos mulher já se colocava no mundo ocidental desde, pelo menos, o que ficou conhecido como a Querelle des Femmes na França, entre os séculos XV e XVIII. Esta disputa, que começa com a resposta de Christine de Pizan La Cité des dames ao Roman de la Rose de Guillaume de Lorris e Jean de Meun. A querelle apresenta alguns exemplos de homens e mulheres que defendiam a educação igualitária sem distinção de sexo. Sobre isso ver: VIENNOT, É. La querelle des femmes ou «n'en parlons plus » Éditions iXe, 2019 e DORLIN, E. L’évidence de l'égalité des sexes : Une philosophie oubliée du XVII siècle. Paris: L'Harmattan, 2000. 
silenciamento e esvaziamento de nossas vozes. Se o negro foi racializado pelo branco e a mulher generificada pelo homem, por que a repulsa pelo movimento que agora estabelece uma racialização do corpo branco e uma generificação do sexo masculino? Reformulando a partir do ferramental teórico que me foi disposto pela filosofia canônica, se a existência precede a essência, por que o corpo branco, masculino e europeu foi assimilado como uma testemunha modesta, o sujeito do conhecimento objetivo? E por que devemos seguir em uma espécie de negação de nossas singularidades? Construir uma epistemologia feminista, nesse sentido, é uma ação pedagógica e política contra as limitações identitárias que nos foram impostas ao longo da história. Afinal, se a casa nos é de tal modo imposta e, ao mesmo tempo, constitutiva de nossa subjetividade, por que não analisá-la em nossas produções intelectuais?

A casa, entretanto, não é mais a mesma com a intrusão da pandemia. Contrária às leis da natureza, ela diminuiu em espaço e aumentou em tempo. Se antes passávamos três horas em média no transporte público, de quatro a seis horas nas universidades e escolas, e mais umas tantas outras horas que "sobravam" dedicadas ao trabalho reprodutivo, seja para comigo, seja para com outros que dependem diretamente de mim, agora tudo isso foi reduzido ao lar. Não há mais separação entre o lugar da família e do trabalho. Como manter a separação entre público e privado, tão característica da neutralidade e objetividade modernas, em tempos de catástrofes? O vírus faz parte da dinâmica da vida, da biosfera, é o resultado de nosso modo moderno de estar no mundo. Mas como lidamos com suas implicações, como gerenciamos a crise advinda dessa relação desigual passa por uma relação ainda mais próxima entre ciência, política e sociedade.

A participação de mulheres (brancas, negras, indígenas, cis e trans) em espaços políticos, acadêmicos, culturais e outros historicamente dominados pelo público masculino e, sobretudo, branco é acompanhada da constatação de que grande parte das mulheres periféricas seguem sem uma mudança efetiva em termos econômicos e sociais. São trabalhadoras que hoje, em meio a uma pandemia que escancara nossas mazelas sociais, sobrevivem com um auxílio emergencial de um governo federal que lhes nega o exercício de uma vida digna ao priorizar um plano econômico neoliberal e uma necropolítica em termos sociais. O projeto não é apenas de desmonte das instituições públicas e enfraquecimento da democracia. Há em curso um plano que coloca entregues à própria sorte todos aqueles que já viviam em condições de precarização social. Como afirma Wendy Browm, "a economicização neoliberal da vida política e social se distingue por uma produção discursiva que converte toda pessoa em capital humano" (BROWN, 2018, p.6). Nossos corpos, nossa existência, são diariamente quantificados por uma política de Estado que visa o lucro de instituições privadas enquanto nega dados técnicos de suas próprias Instituições.

0 trabalho

O entusiasmo no ensino superior era visto como algo que poderia perturbar a atmosfera de seriedade considerada essencial para o processo de aprendizado. Entrar numa sala de aula de faculdade munida de vontade de partilhar o desejo de estimular o entusiasmo era um ato de transgressão.

bell hooks, Ensinando a transgredir, 2013, p. 17.

\section{3 de agosto de 2020}

A Nota técnica do IPEA No 24 publicada em 2016, "Mulheres e trabalho: breve análise do período 2004-2014", questiona a interpretação comumente feita de que as mulheres estariam alijadas do mercado de trabalho ao propor uma revisão da definição do conceito de trabalho. 
Dados dos Censos Demográficos apontam que, em 1970, apenas 18,5\% das mulheres eram economicamente ativas. Em 2010, este valor foi de quase 50\% (ALVES, 2013). Sobre isso, cabem algumas ressalvas. Primeiro, é importante mencionar que as mulheres não estiveram sempre fora do mercado de trabalho. "Os primeiros dados oficiais de que se tem conhecimento apontam que, em 1872, elas representavam $45,5 \%$ da força de trabalho. Nesta época (...) as mulheres estavam empregadas predominantemente na agropecuária, nos serviços domésticos em lar alheio ou no serviço de costura por conta própria. Depois de 1920, a PEA [População Economicamente Ativa] feminina reduz-se drasticamente, em parte porque no momento do primeiro recenseamento boa parte da produção se desenvolvia nos limites domésticos" (Ipea, 2014, p.592). Em segundo lugar, as mulheres não estiveram fora do mercado na mesma medida. Para as mulheres negras, por exemplo, submetidas a condições de vida significativamente mais precárias, a "alternativa" de manter-se fora do mercado apresentou-se com muito menos intensidade e, desde muito cedo, estas mulheres trabalhavam fora de casa para trazer renda às famílias, ainda que esta renda fosse, já naquele momento, percebida como adicional, secundária ou complementar. (IPEA, Mulheres e trabalho: breve análise do período 2004-2014, Nota técnica No24, 2016, p.5).

A nota orienta que o que se entende por trabalho, à luz de um recorte de gênero, raça e classe, deve levar em consideração tanto o trabalho produtivo, voltado para a produção de bens e serviços, quanto o trabalho reprodutivo, dedicado à manutenção da vida humana. Ou seja, mulheres, e sobretudo mulheres negras, há muito constituem uma parte fundamental da força de trabalho mantenedora do capital, mas foram invisibilizadas por pesquisas que restringiam o conceito de trabalhador às ideias de produção e mercantilização. Em tempos de crise, como a pandemia que passamos, mulheres que precisam se dedicar ao trabalho reprodutivo, mulheres trabalhadoras rurais, que trabalham na agricultura familiar e mulheres periféricas sofrem ainda mais com a precarização de suas condições de existência. No universo da pesquisa acadêmica, também não nos são asseguradas condições trabalhistas. Pesquisadores pós-graduandos habitam uma espécie de limbo entre o período da formação inicial até a conquista de um posto de docente. A pesquisa, no caso brasileiro, fica atrelada completamente a um cargo de ensino sem levar em conta as habilidades e necessidades específicas que cada atividade exige (VIDEIRA, 2017).

Desde quando começou o confinamento um novo modelo de produção se materializou no mundo virtual. As lives que começaram com um grupo específico da cultura popular, rapidamente foram ganhando espaço entre os acadêmicos. Sobre este tema em específico falo da experiência profícua com o Coletivo Filósofas na Rede (com página própria no instagram, youtube e facebook) que, desde março, o início da quarentena, se afirmou a partir de um grupo de mulheres que se reuniram para encontrar um ambiente seguro entre acadêmicas para debater sobre seus trabalhos e temas atuais. Desse grupo, muitas se conheceram no período de formação em filosofia, outras se encontraram pelo caminho e há mesmo aquelas que seguem a ser conhecidas em um futuro desconfinamento.

As lives do Filósofas tiveram de início o aspecto de uma conversa entre colegas de vida e profissão, passou rapidamente para uma dinâmica de entrevista entre pares de diferentes áreas da academia e dos movimentos sociais e, agora, privilegia um ambiente de roda, de diálogo aberto sobre temas urgentes. Para além deste projeto do qual faço parte, outras iniciativas de mulheres filósofas foram expressivas nesse período como: O Afrikafecomaspretas, As Pensadoras (Curso e Instituto), a Rede Brasileira de Filósofas e o Coletivo Noéli, do qual também faço parte, que apresenta, sobretudo com a produção escrita e visual de graduandas e graduadas em Filosofia da Uerj, uma releitura do cânone filosófico com recorte de gênero. $\mathrm{O}$ ambiente virtual foi assimilado por uma parte dos acadêmicos como uma possibilidade de manter o contato com um mundo que se havia perdido. A substituição da experiência física pela troca online está longe de ser completa, mas deve ser analisada a partir do momento que vivemos como o que é: uma ferramenta, não o próprio pensamento. Afinal, se assentimos que a ciência tem algum grau de certeza em suas previsões e demonstrações, é preciso manter o distanciamento social para proteger a si e aos outros com os quais convivo, e na maior parte das vezes são mais frágeis ao vírus. O trabalho, para aqueles que podem, passou ao teletrabalho. Ainda que com 
alguma resistência, sobretudo quanto à mera substituição do ensino presencial pelo ensino à distância, a troca entre pares interessados em promover algum debate que diminuísse a distância entre as pessoas confinadas e ainda fomentasse a divulgação científica se estabeleceu em algumas frentes e muitas delas de grupos historicamente oprimidos, como de negros e mulheres.

O mundo fechado do comentarismo de autores (MENDONÇA, 2017), como, se não o único, ao menos o principal instrumento de produção do conhecimento orquestrado pela academia brasileira, foi, uma vez mais, posto em questão por meio do universo da comunicação audiovisual enquanto mecanismo de divulgação científica aberto a novos agentes. Não se trata de uma abertura totalmente democrática, uma vez que o acesso ao conteúdo e a própria produção de conteúdo digital, seja ele síncrono ou assíncrono, depende de um serviço privatizado que não chega a inúmeras famílias ou chega de forma precária. Mas se o cinema se faz com uma câmera na mão e uma ideia na cabeça, as Filósofas ensaiam resistir ao confinamento - político, de nossas ideias historicamente silenciadas, e social, de nossos corpos - por meio do encontro de ideias em rede.

Ainda que o tempo seja muito facilmente absorvido pelo trabalho diário que se coloca como um obstáculo à dedicação ao trabalho acadêmico, nunca me expus tão frequentemente nem tive a oportunidade de ver $\mathrm{e}$ ouvir tantas mulheres acadêmicas falando sobre seus trabalhos e suas impressões e análises quanto ao tempo presente. Acompanhar um diálogo entre mulheres, nesse caso separadas fisicamente, mas conectadas pelo pensamento, é poder observar tanto a razão em plena atividade quanto o alcance que essas vozes conquistaram.

Em resumo, há em curso uma virada filosófica efetivamente feminista que passa pela seguinte compreensão: não há agora e talvez antes também não houvesse uma política efetiva para mulheres que não inclua uma ressignificação dos espaços público e privado que desnaturalize as relações binárias de gênero e as opressões interseccionais de raça e classe. Se nossas jornadas há muito são multiplicadas, como tentar nos fazer caber nesse método que exige uma existência livre de determinações prévias? Não teríamos chance alguma nesse lugar, seguiríamos como alguns exemplares, exceções, tal como as eruditas europeias do início da modernidade que denotavam em si a justificativa de que há qualquer coisa entre a meritocracia e a natureza de um intelecto feminino instrumentalizado a ser respeitado. Não há.

\section{0 conhecimento}

Eu chamo de IGUAÇUANO

Quem luta e nunca desiste Quem espera todo ano A água que não existe Quem bate o pé e reclama E borra a calça de lama Quem se atola mas resiste.
Eu chamo de IGUAÇUINO

O porco, sujo, canalha

"Operação pente fino"

Babá da politicalha

Quem mete bronca e arruma

Enfia a mão e se apruma

E o Município emporcalha.

Tem politiqueiro assim
Tem candidato também Sem princípio, meio e fim Que só vai mal, vai e vem Entrou pobre e saiu rico A cachola é um pinico Mas é "doutor" gente bem.

(...)

(Ney Alberto, Em Nova Iguaçu depois da tempestade vem a lambança, 1979)

É engraçado como eles gozam a gente quando a gente diz que é Framengo. Chamam a gente de ignorante dizendo que a gente fala errado. $\mathrm{E}$ de repente ignoram que a presença desse $\mathrm{r}$ no lugar do $\mathrm{l}$, nada mais é que a marca linguística de um idioma africano, no qual o $l$ inexiste. Afinal, quem que é o ignorante? Ao mesmo tempo, acham o maior barato a fala dita brasileira, que corta os erres dos infinitivos verbais, que condensa você em cê, o está em tá e por aí afora. Não sacam que tão falando pretuguês (Lélia Gonzales, Racismo e sexismo na cultura brasileira, 1984, p.238). 
A noção de uma emancipação feminina conquistada pelo trabalho pessoal, o mérito próprio, é o verdadeiro fantasma do feminismo branco radical e liberal que assombra a todas nós que nos lançamos sobre o pensamento crítico feminista. A noção de um ponto de vista feminista (feminist standpoint) exclui a possibilidade de uma identidade única ao afirmar que a experiência de ser mulher se dá de forma social e historicamente determinada (BAIRROS, 1995, p.461).

Quando endereço esse ensaio às mulheres acadêmicas periféricas não pretendo, com isso, reduzir a um único modelo todas as nossas experiências possíveis, mas salientar que o conhecimento científico, a despeito das intenções de uma parcela de seus agentes comuns, não está livre dos marcadores sociais que operam em nossas construções subjetivas. Mesmo no contexto territorial em que me encontro, há outras periferias ainda mais profundas em comparação com a que habito. Mulheres e homens negros seguem compondo uma parte ínfima, figuras exemplares, no corpo discente e docente da academia. Não nos enganemos, não se trata de diferentes privilégios, mas de um acesso desigual a direitos fundamentais. O problema é estrutural.

\section{6 de agosto de 2020}

Um ensaio sobre a ciência em suas relações possíveis com os feminismos abre uma dupla significação quanto à forma. Trata-se, enquanto estilo literário, de percorrer de modo crítico um tema em sua complexidade, ainda que não em sua totalidade. Por outro lado, exige também uma atenção em uma outra direção que corresponde ao verbo "ensaiar", no sentido mesmo de testar, pôr à prova uma hipótese. Quanto a isso, gostaríamos de afirmar que se há uma hipótese aqui a ser testada trata-se justamente da impossibilidade de pensarmos de modo filosófico uma ciência isolada da sociedade. Entendo a relação entre ciência e feminismos nesse duplo jogo que um ensaio evoca. Não pretendo, com isso, atacar às práticas científicas, mas "defendê-las contra uma imagem de autoridade alheia ao que constitui sua fecundidade e sua relativa confiabilidade" (STENGERS, 2015, p.63).

Em tempos de pandemia, a função da divulgação do conhecimento científico é ainda mais elevada para fazer corresponder de maneira responsável um conhecimento fiável e o entendimento público. A diversidade que compõe a agência da produção de conhecimento científico pode e deve auxiliar nesse desafio. Quando há muito os Science Studies questionam o para quê e o para quem as ciências são feitas, trata-se não apenas de reconhecer os limites de uma análise autocentrada na cisão entre fatos e valores, mas de reconhecer na pluralidade metodológica científica seu princípio fundador.

Se tivesse de resumir em uma palavra aquilo que distingue a produção de conhecimento científico de outras atividades humanas, afirmaria, longe das tentativas de definições metodológicas últimas, a importância do tempo. A comunidade científica, mesmo em tempos de crise pela qual passamos, opera a partir de uma dinâmica de pesquisa que é completamente contrária à instantaneidade característica do universo da produção de conteúdo digital. A divulgação do conhecimento científico produzida pelas próprias Instituições científicas também demanda um tempo consideravelmente maior para que haja uma avaliação entre pares que a certifiquem. Se por um lado a avaliação às cegas, entre pares, é acusada de reproduzir um determinado tipo de conteúdo, por outro ela assegura um parecer independente do viés de gênero, raça e classe de seus autores. Por isso, uma epistemologia feminista não pode visar apenas a representatividade, uma vez que não se trata mais de uma assinatura do texto, ou o quem o escreve, mas sobre o que e como ele é produzido.

A função do tempo para a produção de conhecimento é, portanto, a de ser refratária à imprecisão, ao descuido. Ainda que a sociedade se incline ao espetáculo e às fórmulas simples sobre ciência, a intrusão de cientistas no meio digital não deve perder de vista a vocação nem mesmo a disposição que nosso trabalho de pesquisa exige. Como mulheres acadêmicas de origem periférica, nossa escrita é híbrida quanto a sua territorialização porque mescla tanto nosso lugar de origem quanto o das outras culturas a que fomos oportunizadas a conhecer. Nossa língua ressoa as muitas vozes que compuseram nossa trajetória acadêmica e pessoal e isso nos leva a uma localização fronteiriça. Essa ressonância nos leva a uma identidade descentralizada e 
em constante mutação (HALL, 2005, p. 13) que se afirma em sua produção diversa. Esse entendimento de si para além do status de Outro que nos impuseram, ou seja, nos entendermos enquanto produtoras e não meras reprodutoras de conhecimento pode produzir mudanças estruturais no modo como a ciência se faz.

Se o cânone nos rejeita, talvez seja a hora de ressignificarmos suas estruturas a fim de reescrevê-lo a partir de baixo (HARDING, 2019), da periferia, ou mesmo de operar por estruturas que independam de tal pretensão universalizante. A ciência e o conhecimento que ela produz não são alheios aos marcadores interseccionais de diferença. Afinal, eles dependem de investimento financeiro e apoio institucional, o que explicita seu caráter situado, mas nem por isso as periferias regionais e humanas deixaram de produzir ou participar da ciência, como procuramos aqui demonstrar. Acreditamos que as produções coletivas, anteriormente citadas, nesse período pandêmico, lançam luz sobre uma diversidade de mundos culturais que viabilizam a reflexão sobre o cânone, ou ainda, como indica Hebe Vessuri (2019, p.29), a possibilidade de uma ciência sem cânone.

Assim, me despeço na esperança de que esse ensaio-epistolar lhe seja frutífero e que sejamos ainda muitas em rede a iluminar nossos caminhos.

\section{Referências}

ANZALDÚA, Gloria. Falando em línguas: uma carta para as mulheres escritoras do terceiro mundo. Revista Estudos Feministas, Florianópolis, v. 8, n. 1, p. 229, jan. 2000. ISSN 1806-9584. Disponível em: <https://periodicos.ufsc.br/index.php/ref/article/view/9880/9106>. Acesso em: 26 ago. 2020. doi: https://doi.org/10.1590/\%x.

BAIRROS, Luiza. Nossos feminismos revisitados. Revista Estudos Feministas, Florianópolis, v. 3, n. 2, p. 458, jan. 1995. ISSN 1806-9584. Disponível em: <https://periodicos.ufsc.br/index.php/ref/article/view/16462/15034>. Acesso em: 26 ago. 2020. doi: https://doi.org/10.1590/\%x.

BROWN, W. Cidadania Sacrificial: Neoliberalismo, capital humano e políticas de austeridade. LEÃO, Juliane Bianchi (Trad.). Zazie Edições, 2018.

GONZALES, Lélia. Racismo e sexismo na cultura brasileira, Revista Ciências Sociais Hoje, Anpocs, 1984, p. 223-244.

HALL, Stuart. A identidade cultural na pós-modernidade. SILVA, Tomaz Tadeu; LOURO, Guacira Lopes (Trad.). 10 ed. Rio de Janeiro: DP\&A, 2005.

HARAWAY, Donna. Modest-Witness@Second-Millennium. FemaleMan-Meets-OncoMouse: feminism and technoscience, $2^{\mathrm{a}}$ ed. Nova York: Routledge, 2018.

HARDING, S. Objetividade mais forte para ciências exercidas a partir de baixo de Sandra Harding, Revista Em Construção: arquivos de epistemologia histórica e estudos de ciência, ano 3, n. 5, 2019.

HARDING, S. A instabilidade das categorias analíticas na teoria feminista. R. Estudos Feministas. n. 1, 1993, p. 7-31.

MENDONÇA, A. Manifesto da Filosofia Pau-Brasil: da Filosofia na Ágora à Filosofia de Agora. E de Volta para o 'Futuro Passado'! Revista Em Construção: arquivos de epistemologia histórica e estudos de ciência, ano 1, n. 1, 2017, pp. 106-122.

SHAPIN, Steven; SCHAFFER, Simon. Leviathan and the Air-Pump: Hobbes, Boyle, and the Experimental Life. Princeton: Princeton University Press, 1985.

STENGERS, Isabelle, No tempo das catástrofes - resistir à barbárie que se aproxima. São Paulo: Cosac Naify, 2017.

VESSURI, Hebe, Crises that mismatch canons in science: provincialization, transnationality, conviviality? Tapuya: Latin American Science, Technology and Society, vol. 2, n. 1, 2019, p.26-31. DOI:10.1080/25729861.2019.158619

VIDEIRA, Antonio L. L. Plínio Sussekind Rocha: um mestre "excêntrico". Em Construção: arquivos de epistemologia histórica e estudos de ciência, ano 1, n. 2, pags. 263 - 269, 2017. 